\title{
Jones-matrix tomography of biological tissues phase anisotropy in the diagnosis of uterus wall prolapse
}

\author{
L. Trifonyuk ${ }^{1}$, V. Baranovsky ${ }^{2}$, O.V. Dubolazov ${ }^{3}$, V.O. Ushenko ${ }^{3}$, O.G. Ushenko ${ }^{3}$, \\ V.G. Zhytaryuk ${ }^{3}$, O.G. Prydiy ${ }^{3}$, O. Vanchulyak ${ }^{1}$ \\ ${ }^{1}$ Rivne State Medical Center, 78 Kyivska Str., Rivne, Ukaraine, 33007 \\ ${ }^{2}$ Warsaw Military Institute of Medicine, Warsaw, Poland, 04141 \\ ${ }^{3}$ Chernivtsi National University, 2 Kotsiubynskyi Str., Chernivtsi, Ukraine, 58012
}

\begin{abstract}
The work consists of two parts. In the first part - we mapped a distribution of optical activity and birefringence in polycrystalline networks of biological tissues. The Jones-matrix formalism is used for accessible quantitative description of these types of optical anisotropy. We demonstrate that differentiation of polycrystalline networks of biological tissues can be performed based on the statistical analysis of distribution of rotation angles and phase shifts associated with the optical activity and birefringence, respectively. In the second part we defined - practical operational characteristics, such as sensitivity, specificity and accuracy of Jones-matrix reconstruction of optical anisotropy were identified with the special emphasis on biomedical application, specifically for differentiation of two types of pathology: prolapse and albuminuria.
\end{abstract}

Keywords: Johnes matrix, biological tissue, anisotropy, tomography, diagnostic.

\section{THEORETICAL BASICS AND EXPERIMENTAL REALIZATION OF JONES-MATRIX MAPPING OF BIOLOGICAL LAYERS BIREFRINGENCE}

\subsection{Jones-matrix reconstruction of parameters of linear and circular birefringence}

In the ground of this work it has been chosen the matrix approach for investigation of the structure of biological objects ${ }^{1-}$

14. Theoretical backgrounds of the method of mapping of anisotropy parameters of polycrystalline component of biological layers are in details provided in the set of works ${ }^{15-30}$.

In ${ }^{14,15}$ it was suggested a new form of Jones matrices.

$$
\{J\}=\left\|\begin{array}{ll}
R_{11}(r) \exp \Theta_{11}(r) & R_{12}(r) \exp \Theta_{12}(r) \|, \\
R_{21}(r) \exp \Theta_{21}(r) & R_{22}(r) \exp \Theta_{22}(r)
\end{array}\right\|,
$$

Here matrix $\{J\}$ is written as real $R_{i k}$ (modulus) and imaginary (phase angles) $\Theta_{i k}$ components. On this basis (1) in $^{1-3}$ obtain the algorithms of polarization reproduction of phase anisotropy parameters of optically thin birefringent layer

$$
\begin{gathered}
\delta=\frac{2 \arccos \left(J_{11}+J_{22}\right)}{1+\frac{J_{12}-J_{21}}{J_{22}-J_{11}}}=\frac{2 \arccos \left(R_{11} \cos \Theta_{11}+R_{22} \cos \Theta_{22}\right)}{1+\frac{R_{12} \cos \Theta_{12}-R_{21} \cos \Theta_{21}}{R_{22} \cos \Theta_{22}-R_{11} \cos \Theta_{11}}} \\
\theta=\frac{2 \arccos \left(J_{11}+J_{22}\right)}{1+\frac{J_{22}-J_{11}}{J_{12}-J_{21}}}=\frac{2 \arccos \left(R_{11} \cos \Theta_{11}+R_{22} \cos \Theta_{22}\right)}{1+\frac{R_{22} \cos \Theta_{22}-R_{11} \cos \Theta_{11}}{R_{12} \cos \Theta_{22}-R_{21} \cos \Theta_{11}}}
\end{gathered}
$$




\subsection{Experimental results of the method of birefringence mapping of biological layers}

The measurements of coordinate distributions of Jones-matrix elements were performed in the setup (Fig.1).

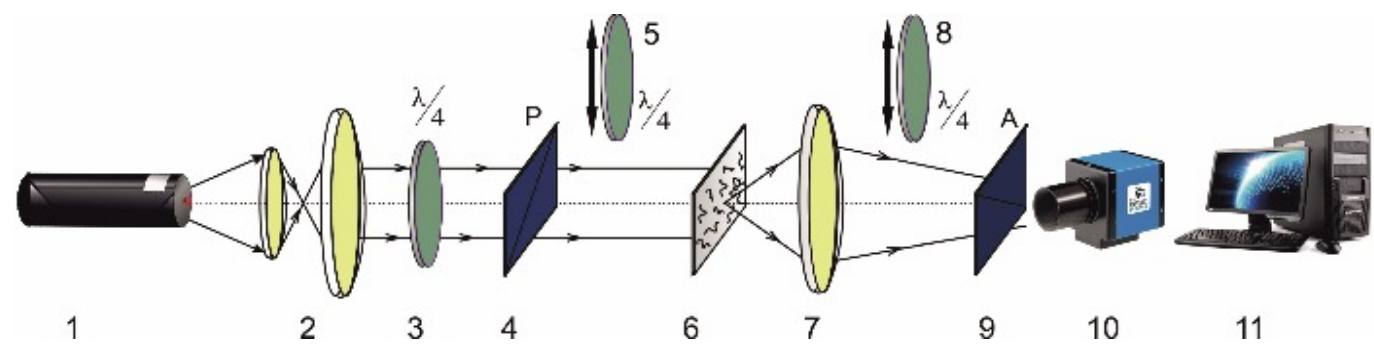

Fig.1. Optical scheme of experimental setup: 1 - He-Ne laser; 2 - collimator; 3 - stationary quarter-wave plate; 5, 8 - mechanically movable quarter-wave plates; 4,9 - polarizer and analyzer respectively; 6 - object of investigation; 7 - optical system; 10 - CCD camera; 11 - PC.

Measurements of real $R_{i k}$ and imaginary $\Theta_{i k}$ parts of Jones-matrix elements (relation (1)) were performed due to the standard technique ${ }^{1-3}$.

As the object of investigation we used a histological section of skin derma. The main anisotropic structures of such an object are collagen fibrils with linear and circular birefringences. The values of such parameters are most adequately described by phase parameters $\delta$ (relation (1)) and $\theta$ (relation (2)) ${ }^{1-3}$.

Fig. 2 presents the maps (fragments $(1,3)$ ) and histograms (fragments $(2,4)$ ) of the distributions of the values of phase shifts of linear (fragments $(1,2)$ ) and circular (fragments $(3,4)$ ) birefringences of the histological section of skin derma.

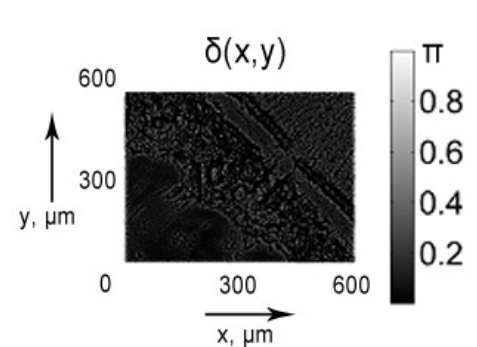

(1)

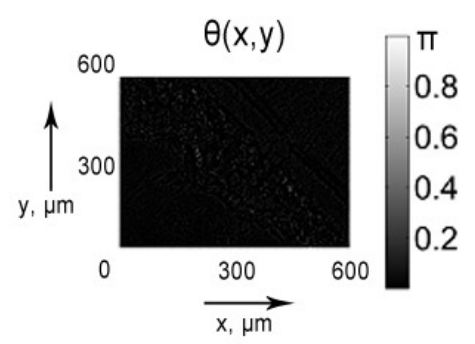

(3)

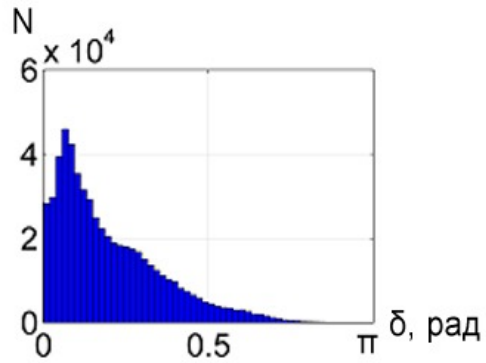

(2)

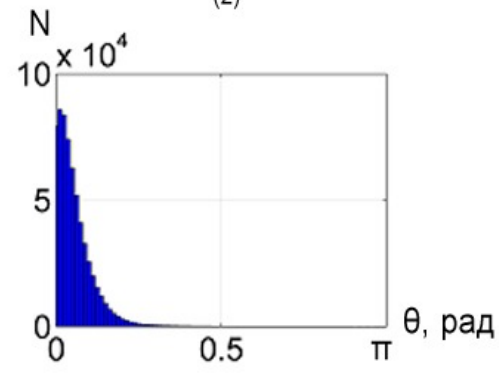

(4)

Fig. 2. Maps (fragments (1),(3)) and histograms (fragments $(2,4)$ ) of the distributions of the values of phase shifts of linear (fragments $(1,2)$ ) and circular (fragments $(3,4))$ birefringences of the histological section of skin derma. 
Table 1 presents the results of statistic analysis (statistical moments of the 1 st- 4 th orders $Z_{i=1 ; 2 ; 3 ; 4}$ ) of coordinate distributions of the phase shifts values of linear (relation (2)) and circular (relation (3)) birefringence of the histological section of skin derma.

Table 1. Statistical moments $Z_{i=1 ; 2 ; 3 ; 4}$ of the distributions of MMI of anisotropy of skin derma tissue

\begin{tabular}{|c|c|c|}
\hline$Z_{i=1 ; 2 ; 3 ; 4}$ & $\delta$ & $\theta$ \\
\hline$Z_{i=1}$ & 0.14 & 0,09 \\
\hline$Z_{i=2}$ & 0,12 & 0.07 \\
\hline$Z_{i=3}$ & 0.71 & 1.27 \\
\hline$Z_{i=4}$ & 0.84 & 2.19 \\
\hline
\end{tabular}

It was defined the individual sensitivity of the value of $Z_{i=1 ; 2 ; 3 ; 4}$ to the peculiarities of MMI coordinate distributions of parameters of linear and circular birefringence of the skin derma tissue. Such a fact was chosen as the basic for applied biomedical usage of statistic analysis of coordinate distributions of linear and circular birefringence parameters.

\section{CLINICAL APPLICATION OF JONES-MATRIX MAPPING OF BIREFRINGENCE IN DIFFERENTIAL DIAGNOSTICS OF PATHOLOGIES OF HUMAN INTERNAL ORGANS}

\subsection{Objects of investigation}

It was investigated two groups of samples of histological sections of biopsy of uterus wall tissue:

- $\quad$ normal - group 1 (32 samples);

- prolapse - group 2 (32 samples).

Histological sections were produced due to the standard technique on the freezing microtome.

Polycrystalline films of urine:

- $\quad$ normal - group 3 (32 samples);

- albuminuria - group 4 (32 samples).

\subsection{Experimental results}

The set of Figs. 3, 4 presents the results of mapping of phase parameters of linear (Fig. 3) and circular (Fig. 4) birefringence of histological sections of biopsy of patients from group 1 (fragments $(1,2)$ ) and group 2 (fragments $(3,4)$ ). 


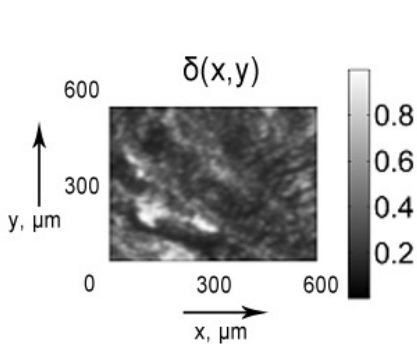

(1)

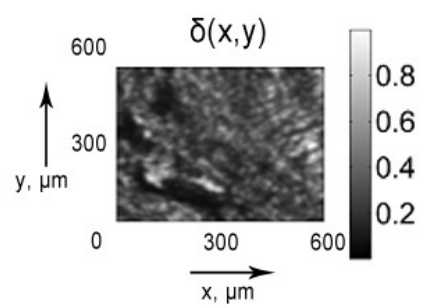

(3)

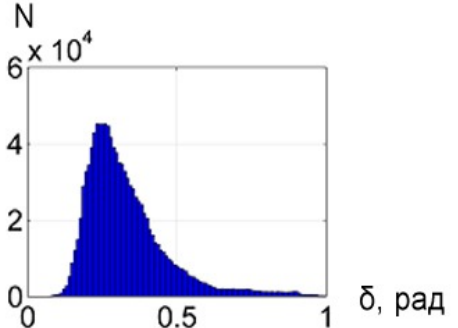

(2)

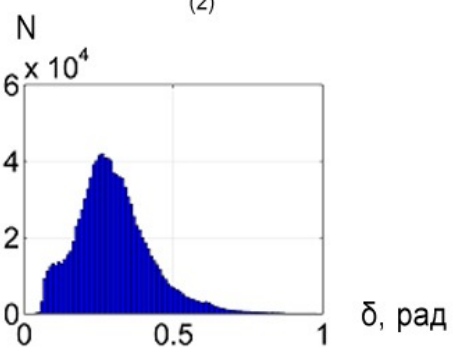

(4)

Fig. 3. Maps (fragments (1),(3)) and histograms (fragments $(2,4)$ ) of the distributions of the values of phase shifts of linear (fragments $(1,2)$ ) birefringence of the histological sections of uterus wall tissue of patients from group 1 (fragments (1),(2)) and group 2 (fragments (3),(4)).

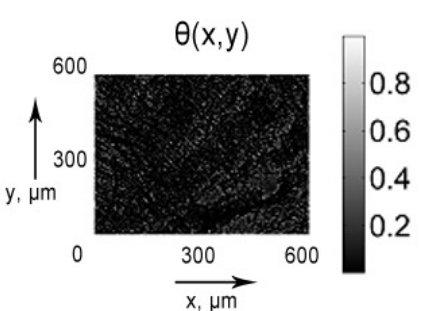

(1)

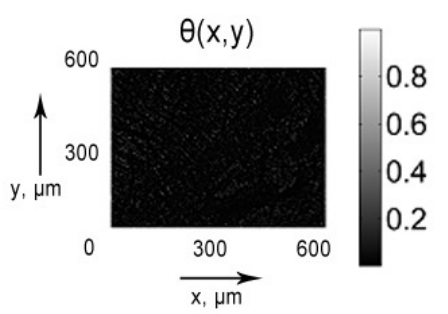

(3)

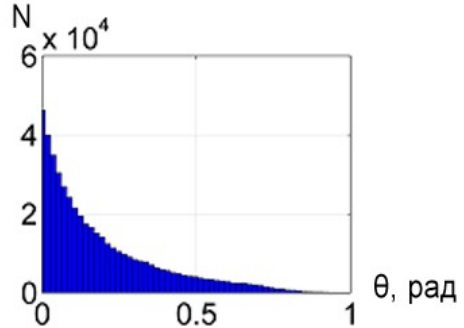

(2)

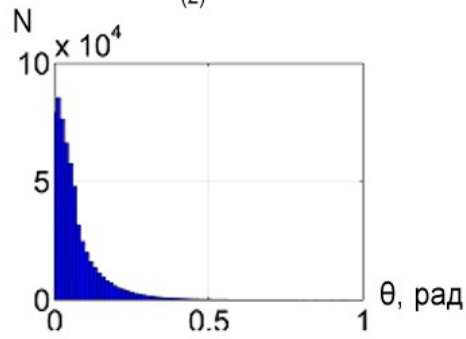

(4)

Fig. 4. Maps (fragments (1),(3)) and histograms (fragments $(2,4)$ ) of the distributions of the values of phase shifts of circular (fragments $(1,2)$ ) birefringence of the histological sections of uterus wall tissue of patients from group 1 (fragments (1),(2)) and group 2 (fragments (3),(4)).

For the possible clinical application of the Mueller matrix mapping method for each group of samples the operating characteristics, typical for evidence-based medicine ${ }^{32-34}$ that determine the diagnostic power of the method are determined, namely - sensitivity $\left(S e=\frac{a}{a+b} 100 \%\right)$, specificity $\left(S p=\frac{c}{c+d} 100 \%\right)$ and balanced accuracy 
$\left(A c=\frac{S e+S p}{2}\right.$ ), where $a$ and $b-$ the number of correct and incorrect diagnoses within group $2 ; c$ and $d$ - the same within group 1 - Table 2 and Table 3.

Table 2. Balanced accuracy of method of Jones-matrix mapping of linear and circular birefringence of uterus wall tissue

\begin{tabular}{|c|c|c|}
\hline$A c, \%$ & $\delta$ & $\vartheta$ \\
\hline$Z_{i=1}$ & $71 \%$ & $68 \%$ \\
\hline$Z_{i=2}$ & $73 \%$ & $71 \%$ \\
\hline$Z_{i=3}$ & $92 \%$ & $84 \%$ \\
\hline$Z_{i=4}$ & $95 \%$ & $87 \%$ \\
\hline
\end{tabular}

It was reached a good $(A c(\vartheta)=84 \%-87 \%)$ and excellent $(A c(\delta)=93 \%-96 \%)$ level of balanced accuracy of the method of Jones-matrix mapping of linear and circular birefringence in the task of differentiation between normal tissue of the uterus wall and with prolapse.

Table 3. Balanced accuracy of method of Jones-matrix mapping of linear and circular birefringence of polycrystalline film of urine

\begin{tabular}{|c|c|c|}
\hline$A c, \%$ & $\delta$ & $\vartheta$ \\
\hline$Z_{i=1}$ & $71 \%$ & $79 \%$ \\
\hline$Z_{i=2}$ & $73 \%$ & $84 \%$ \\
\hline$Z_{i=3}$ & $83 \%$ & $92 \%$ \\
\hline$Z_{i=4}$ & $86 \%$ & $94 \%$ \\
\hline
\end{tabular}

It was reached a good $(A c(\delta)=83 \%-86 \%)$ and excellent $(A c(\theta)=92 \%-94 \%)$ level of balanced accuracy of the method of Jones-matrix mapping of linear and circular birefringence in the task of differentiation between normal and albuminuria patients.

\section{CONCLUSIONS}

Short theoretical basics of the method of azimuthally invariant Jones-matrix mapping of the distribution of birefringence parameters (linear and circular birefringences) of polycrystalline structure of biological layers were provided.

It was demonstrated the results of experimental approbation of such method and defined the distributions of Jones-matrix invariants of linear and circular birefringence of skin derma tissue.

The differentiation of linear and circular birefringence was realized with good and excellent levels of balanced accuracy of differentiation between normal uterus wall tissue and with prolapse; normal and albuminuria patients.

\section{REFERENCES}

[1] Alexander G. Ushenko and Vasilii P. Pishak, "Laser Polarimetry of Biological Tissue: Principles and Applications", in Handbook of Coherent-Domain Optical Methods: Biomedical Diagnostics, Environmental and Material Science, vol. I, Valery V. Tuchin, Ed. Boston: Kluwer Academic Publishers, 2004, pp. 93-138.

[2] Angelsky, O.V., Bekshaev, A. Ya., Maksimyak, P. P., Maksimyak, A. P., Hanson, S.G. ,Zenkova, C. Yu., "Selfaction of continuous laser radiation and Pearcey diffraction in a water suspension with light-absorbing particles," Optics Express 22(3), 2267-2277 (2014).

[3] Angelsky, O. V., Bekshaev, A. Ya., Maksimyak, P. P., Maksimyak, A. P., Hanson, S. G., "Measurement of small light absorption in microparticles by means of optically induced rotation," Optics Express 23(6), 71527163 (2015).

[4] V.V. Tuchin, Tissue Optics: Light Scattering Methods and Instruments for Medical Diagnosis, second edition, SPIE Press, Bellingham, WA, PM 166, 2007. 
[5] S. Bickel, W. M. Bailey, Stokes vectors, Mueller matrices, and polarization of scattered light, Am. J. Phys. 53 (1985) 468-478.

[6] X. Wang, G. Yao, L., H. Wang, Monte Carlo model and single-scattering approximation of polarized light propagation in turbid media containing glucose, Appl. Opt. 41 (2002) 792-801.

[7] X. Wang, L. - H. Wang, Propagation of polarized light in birefringent turbid media: a Monte Carlo study, J. Biomed. Opt. 7 (2002) 279-290.

[8] Polyanskii, V.K., Angelsky, O.V., Polyanskii, P.V., "Scattering-induced spectral changes as a singular optical effect," Optica Applicata 32 (4), 843-848 (2002).

[9] Angelsky, O.V., Besaha, R.N., Mokhun, A.I., Mokhun, I.I., Sopin, M.O., Soskin, M.S., "Singularities in vectoral fields," Proc. SPIE 3904, 40-54 (1999).

[10] Angelsky, O.V., Tomka, Y.Y., Ushenko, A.G., Ushenko, Y.G., Yermolenko, S.B., "2-D tomography of biotissue images in pre-clinic diagnostics of their pre-cancer states," Proc. SPIE 5972, 158-162 (2005).

[11] Ushenko, A.G., Burkovets, D.N., Ushenko, Yu.A. "Polarization Phase Mapping and Reconstruction of Biological Tissue Architectonics during Diagnosis of Pathological Lesions," Optics and Spectroscopy 93 (3), 449-456, (2002).

[12] V. V. Tuchin, L. Wang, and D. A` . Zimnyakov, Optical Polarization in Biomedical Applications, New York, USA, 2006.

[13]R. A. Chipman, Polarimetry in Handbook of Optics: Vol. I- Geometrical and Physical Optics, Polarized Light, Components and Instruments, M. Bass, Ed., McGraw-Hill Professional, New York, 2010, pp. 22.1-22.37.

[14]D. K. Kasaragod et al., "Experimental validation of an extended Jones matrix calculus model to study the 3D structural orientation of the collagen fibers in articular cartilage using polarization-sensitive optical coherence tomography," Biomed. Opt. Express 3(3), 378-387 (2012).

[15]Y. Yasuno et al., "Jones Matrix based polarization sensitive optical coherence tomography," in Optical Coherence Tomography: Technology and Applications, 2nd ed., W. Drexler and J. G. Fujimoto, Eds., pp. 11371162, Springer Reference, Science + Business Media, New York (2015)

[16] J. Tervo, T. Setala, A. Friberg, "Degree of coherence for electromagnetic fields," Opt. Express 11, 1137-1143 (2003).

[17] Yu.A. Ushenko, V.A. Ushenko, A.V. Dubolazov, V.O. Balanetskaya, N.I. Zabolotna, "Mueller-matrix diagnostics of optical properties of polycrystalline networks of human blood plasma," Optics and Spectroscopy 112, 884-892 (2012).

[18] V.A. Ushenko, O.V. Dubolazov, A.O. Karachevtsev, "Two wavelength Mueller matrix reconstruction of blood plasma films polycrystalline structure in diagnostics of breast cancer," Appl. Opt. 53, B128-B139 (2014).

[19] Y.A. Ushenko, G.D. Koval, A.G. Ushenko, O.V. Dubolazov, V.A. Ushenko, O.Yu. Novakovskaia, "Muellermatrix of laser-induced autofluorescence of polycrystalline films of dried peritoneal fluid in diagnostics of endometriosis," J. Biomed. Opt. 21(7), 071116 (2016).

[20] A.G. Ushenko, A.V. Dubolazov, V.A. Ushenko, O.Y. Novakovskaya, "Statistical analysis of polarizationinhomogeneous fourier spectra of laser radiation scattered by human skin in the tasks of differentiation of benign and malignant formations," J. Biomed. Opt., 21(7), 071110 (2016).

[21] V.P. Prysyazhnyuk, Yu.A. Ushenko, A.V. Dubolazov, A.G. Ushenko, V.A. Ushenko, "Polarization-dependent laser autofluorescence of the polycrystalline networks of blood plasma films in the task of liver pathology differentiation,” Appl. Opt. 55, B126-B132 (2016).

[22] Angelsky, O.V., Polyanskii, P.V., Hanson, S.G., "Singular optical coloring of regularly scattered white light," Optics Express 14 (17), 7579-7586 (2006).

[23] Ushenko, A.G., "Laser diagnostics of biofractals," Quantum Electronics 29(12), 1074-1077 (1999).

[24] Angelsky, P. O., Ushenko, A. G., Dubolazov, A. V., Sidor, M. I., Bodnar, G. B., Koval, G., Trifonyuk, L., "The singular approach for processing polarization-inhomogeneous laser images of blood plasma layers," Journal of Optics, 15(4), 044030 (2013).

[25] V. A. Ushenko, A. V. Dubolazov, "Correlation and self similarity structure of polycrystalline network biological layers Mueller matrices images," Proc. SPIE 8856, (2013).

[26] Yu. A. Ushenko, V. A. Ushenko, A. V. Dubolazov, V. O. Balanetskaya, N. I. Zabolotna, "Mueller-matrix diagnostics of optical properties of polycrystalline networks of human blood plasma," Optics and Spectroscopy 112(6), 884-892 (2012).

[27] Yu. A. Ushenko, A. V. Dubolazov, V. O. Balanetskaya, A. O. Karachevtsev, V. A. Ushenko, "Wavelet-analysis of polarization maps of human blood plasma," Optics and Spectroscopy, 113(3), 332-343. (2012). 
[28] Holovatsky, V.A., Makhanets, O.M., Voitsekhivska, O.M., "Oscillator strengths of electron quantum transitions in spherical Nanosystems with donor impurity in the center," Physica E: Low Dimensional Systems and Nanostructures 41(8), 1522-1526 (2009).

[29] Ushenko, O., Dubolazov, A., Balanets' ka, V., Karachevtsev, A., Sydor, M., "Wavelet analysis for polarization inhomogeneous laser images of blood plasma," Proc. SPIE. Vol. 8338 (2011).

[30] Ushenko, A.G., "Polarization Correlometry of Angular Structure in the Microrelief Pattern of Rough Surfaces," Optics and Spectroscopy (English translation of Optika i Spektroskopiya) 92, 227-229 (2002).

[31] V. A. Ushenko, O. V. Dubolazov, A. O. Karachevtsev, "Two wavelength Mueller matrix reconstruction of blood plasma films polycrystalline structure in diagnostics of breast cancer," Applied Optics. 53(10), B128B139 (2014).

[32]L. Cassidy, "Basic concepts of statistical analysis for surgical research," Journal of Surgical Research 128, 199206 (2005).

[33] C. S. Davis, "Statistical methods of the analysis of repeated measurements," New York: Springer-Verlag, 744, (2002).

[34] A. Petrie, B. Sabin, "Medical Statistics at a Glance,” Blackwell Publishing, 157, (2005). 